\title{
Best Education Practices: An Umbrella Term to Talk about a Brazilian Academic Discipline
}

\author{
Maclovia Corrêa da Silva1, Silvania Sousa do Nascimento² \\ ${ }^{1}$ Programa de Pós-Graduação em Tecnologia, DALEM-Departamento Acadêmicos de Línguas Estrangeiras \\ Modernas, Universidade Tecnológica Federal do Paraná (UTFPR), Curitiba, Brazil \\ ${ }^{2}$ Programa de Pós-Graduação em Educação, DMTE-Departamento de Métodos e Técnicas de Ensino, \\ Universidade Federal de Minas Gerais (UFMG), Belo Horizonte, Brazil \\ Email: macloviasilva@utfpr.edu.br, silnascimento@ufmg.br
}

Received 21 September 2015; accepted 22 November 2015; published 25 November 2015

Copyright (C) 2015 by authors and Scientific Research Publishing Inc.

This work is licensed under the Creative Commons Attribution International License (CC BY).

http://creativecommons.org/licenses/by/4.0/

(c) (i) Open Access

\section{Abstract}

The scope of this paper is limited to discipline activities professors and graduated students (master and doctor degrees) at schools regarding aspects of environment and education. Two Brazilian universities contribute to social action with educational, cultural and environmental practices to the constitution of expertise and knowledge. The practices contain relevant research, innovation, critical elements and confidence in creativeness. Activities emphasize theoretical constructs of single topics from different thematic areas to highlight and disseminate educational current practices. We conclude that best practices are a wide range of individual and collective activities and procedures for student's learning. It achieves positive results regarding educational, cultural, environmental expertise and knowledge.

\section{Keywords}

Students, Teachers, Professors, Expertise, Knowledge, Federal University of Technology—Paraná, Universidade Federal de Minas Gerais

\section{Introduction}

The scope of this paper is limited to discipline activities related to aspects of environment and education, with professors and graduated students (master and doctor degrees), employed in small classes of junior high students once a year. At the same time, this means also supplying courses for schools and educators and shared campus 
experiences. The activities emphasize theoretical constructs of single topics, different thematic areas, and disciplinary areas to highlight and disseminate current practices provided in educational community in federal and state schools.

Active teaching and learning in graduated studies has happened since 2011 in two Brazilian universities. In educational contexts, contributing to social action, our discipline was born and baptized in the second semester of 2011as "Educational, cultural and environmental practices to the constitution of expertise and knowledge". Engaging themselves in fieldwork, professors and graduated students explore the relevance of contextual knowledge and expertise appropriation with junior high school students.

We believe that we always learn from each other. As professors and researchers, we undertake interdisciplinary practices in environmental education with diverse perspectives of life, employing a variety of approaches, methods and techniques being exploratory, descriptive, and explanatory.

Over the past five years it had been possible for Universidade Tecnológica Federal do Paraná (PPGTE/ UTFPR) and Universidade Federal de Minas Gerais (PPGEIS/UFMG) to include innovative teaching and learning methods and flexibility in the selection of topics to attend and change students' common needs and nature. Our enthusiasm for the profession of teaching, learning, and researching for social and environmental changes, requires us to use communication via the Internet and the World Wide Web.

Due to a wide variety of activities and approaches of best education practices we would not be free to relate them only to positive change student attitudes and behaviors. The coin has two sides. But for all that, a careful learning activities selection within the classroom, or not, containing detailed information to implement them, makes the difference in teaching creativeness. With theoretical basis, quantitative, qualitative, or mixed design, validated education practices can be constantly modified, improved and also replicated.

In our courses we used a group of practical approaches to improve the classroom active learning experiences mixing concomitant hands-on tasks with junior high school students and discipline practices necessary to innovate with success. Which are the limiting factors? None. We just have to join the social actors and roles to take into account the challenges ahead. Observation and participation are methods that empower us to understand what shall be significantly identified as cultural characteristics to match contexts and student requirements.

Each year, a rich territory of ideas opens regarding the students' performances and personal engagements. The collective bodies of disciplinary knowledge draw evidences and discussions about how to work particular aspects with particular groups of students. To view the practices in different ways and angles we are very knowledgeable to reinterpret teaching methods. To fit with the discipline purposes, we try to achieve genuine understanding and interaction among professors, teachers, and students. We do not prepare the graduated students for a written test but for a meaningful course with thoughtful planning, and planning again and again. Their overall experiences at a particular institution showed them where they were going, and how we could support them to get in the face of successes and failures. They expect to be challenged by coming to schools and develop different aspects of their subjects.

The privilege to work with empirical data collection process is done to a popular research design, testing specific hypotheses: like participant research and case studies, we work the subject's relationships to their context. It is a method inspired in interdisciplinary science and works within a specific socio-cultural, political, and educational situation. Students and professors are immersed in different dimensions for three or four months and during this period we propose, observe, record the daily activities, take personal field notes and use a combination of techniques to get quantitative and qualitative data.

During the course we keep the opportunity to share a scholarly written forum for discussion addressing teaching and learning. We focus on junior high school students as involved learners embracing responsibility in knowledge discovery, creation and understanding of concepts. The pragmatic educational and cultural activities proposed have been explained by evaluators as a contribution to professors, teachers and students learning, and of course to staff and institution development.

The improvement is afforded in opportunities for junior high school students to participate in cross-disciplinary subjects in one classroom. For them, what we offer means diversity, and enlivens the teaching/learning process. In reality, the new strategies concerning the use of emergent contexts and their relation to each other are not to enhance individual learning but to achieve widespread education. Taking a broad look at the range of education practices, the teaching of small classes provides perspectives on topics relevant to inter-disciplinary studies. The ideas expressed allow a reflection upon our practices and theories and help us to refine constantly to achieve best results. Every year we present thoughtful and useful viewpoints covering a wide variety of perspec- 
tives including an interdisciplinary forum for discussion and debate using technology in communication and innovations on teaching.

\section{Literature Review}

In a review of studies of the issues and trends in teaching and learning about society, technology and education, we detached the philosopher Karl Popper. He says that there exists a great quantity of conjectures, false beliefs and theories that can be proven or disproven. Heemann (2001), his pupil, believes that the reductionism conducts the scientific method because it reduces the phenomena to the cause. Studying ethics, he affirms that the human being gives values to the nature, makes choices, has a subjectivity and he is free to innovate and create new values.

Following the author's ideas, there are no disconnected values from cultures, habits and beliefs. All of them emerge with the human being that valorizes the good, the bad, the right and the wrong which determine behaviors and attitudes. Daily, we create and use different kinds of concepts, olds and news, from many disciplines to explain a phenomenon of interest. The distinction between concept and general representation can be done by hierarchy. The concepts are completely different from undetermined significations in the sense that we can just associate a word to the only signification indicated. Since we elaborate concepts after a reflection, we can say that they acquire a logic value for sciences (Rickert, 1997: p. 232).

Our discipline coexists with this emphasis, and we promote formative interventions from current practices, limited to the characteristics, significations or representations of the concept of field knowledge. The graduated students involvement rises regarding the public. They are concerned, specially, about the students learning necessities and the interaction process.

In Brazil, the children are considered vulnerable even though they have rights and duties and have important roles in their social groups. "As children and young people are considered vulnerable, all the researches involving them need to be approved by a research ethic assembly” (Barbosa, 2015: p. 239). So they need adult protection and supervision, and also education. The Unesco guidelines for teacher's training and assessment regarding the document entitled "Strategic Project on Teachers for Latin America and the Caribbean" outline and establish the teachers role to achieve an education of quality is fundamental.

Not forgetting the importance of disciplines and pedagogy, the practice helps us to investigate and apply collective expertise and knowledge. Like any social science research, the unit of analysis of our study refers to the groups. We are interested in studying with the students the development of knowledge, expertise in everyday activities, moments and situations. Their daily behavior and satisfaction is important to us to generate significant learning respecting the student's ways to create their own comprehension and concepts perspectives.

We agree with the Kolb and Kolb (2005) definition of experiential student learning as a pedagogical technique: it is a process of doing and redoing; the conflicts are present; it is a combining of systematic knowledge and adaptation to the world; and it is present our inner person and the outer environment (Austin \& Rust, 2015).

\section{Methods}

The scientific research discovers laws and postulate theories that can explain natural or social phenomena, or in other words, build scientific knowledge. It is an important definition to understand that science is knowledge, always imperfect or even, sometimes, quite far from the truth, but following a methodology: standardized set of techniques to verify replicability, precision, falsifiability and parsimony (Bhattacherjee, 2012). Sciences, when based on their purposes, can be pure and applied. Pure science investigates about laws and their relationships with the objects and force. Applied one, works with the basic science laws in a physical environment.

Social sciences permit a variety of research approaches and can manipulate quantitative and qualitative data. Our discipline follows this type of research. Methods, orientation practices and perspectives change each year and the students are encouraged to begin outlining their position and considering strategies according the public available. First, the ideas are brought to the class and the process is shaped to design a project in innovative ways.

Dealing with contemporary issues at public and private elementary schools provides us new insights and ideas for educational practices. Since then, we are committed to build innovative and provocative knowledge by school practices addressing issues of significance to different students groups. Teleconferencing enables us to collaborate among groups and guest lecturers. The stimulation starts with a problem-oriented topic, increasing 
emphasis on improving the status of teaching and learning, and finishes with evaluation practices in a critical approach.

Considering the topics of interest and importance for all participants, graduated students learn from the moment they start to develop projects by preparing short presentations and discussions in classrooms at schools. It's a real opportunity to share their ideas, draw connections and get multi-dimensionally and interdisciplinary constructive practices. We value this modality show-and-tell style presentation because it is a successful way to better approach the discipline material, lecture, the insightful comments for comprehension and to synthesize diverse viewpoints. The students can explore ideas without inhibitions.

Our research techniques, tools and outlines give relevance for action and maintain flexibility in the selection of theory topics. They offer a comprehensive range of ideas and techniques for specific applications. The general subjects in nature bring advantages to balance the gap between theory and practice and reach those subjects on all interdisciplinary aspects.

Even though, every year, we start without clearly defined guidelines, the discipline goals are to open conversations and collaborations among the participants to increase the quality and depth of student learning strategies and their optimal use of the process. Through social and cultural activities it's possible to give practical value for professors, teachers' and students' interests on conceptualizations, interpretations, and syntheses.

\section{UFMG UTFPR-Case Studies}

\subsection{UFMG Ecological Station (2011)}

At the UFMG Ecological Station, Environmental Education happens all year. Three times a week, students from public and private school come to this place to learn something of nature and values. Our group had the opportunity during 2011 to work with some of them about "dengue infections: myths and realities". The incidence of dengue has been increasing in the number of cases reported in Brazil and it impacts on human health.

The Aedes aegypti adult female mosquito is the primary vector of dengue; it lives in urban habitats and is highly adaptive to temperatures. As the number of reported cases continues to increase, little prevention cares are important like to check for signs of water and mosquito eggs inside tires, plants, vases, waste, water reservoir, storage containers and applying appropriate insecticides. Active monitoring and surveillance to transmitter control and prevention can also be promoted by environmental education practices, with community's participation and mobilization.

Practices were done through dialogues, with questions and answers to exchange ideas, to revise concepts by plantation flowers, reusing material. (Re)designing objects, making paper artifacts in a way to transform the subject comprehensive and to construct new information. What we emphasized the most was to reproduce the expertise, concepts and ideas about prevention and control of diseases. It had been a rich territory to balance myths and realities. The education experiences were something different from the traditional classroom since the Ecological Station was a different configuration space to get the consciousness of the believing power and the scientific argumentation. Then, ateliers were activities that intercepted the school learning and created strategies to review concepts. Common sense and an academic way of organizing the ideas were responsible for the final collective and personal stories.

\subsection{São Miguel, Municipal Elementary and Junior High School (2012)}

In Curitiba, we were engaged in a teachers' environmental project to talk about environment comfort. The project was directed by two school teachers (physical education and geography) and a pedagogue, and the public was junior high school students from 10 to 13 years old. Our group broke the traditional lecture-oriented classroom even though it used the blackboard. Room's size didn’t allow for easy reconfiguration during activities and efforts were distributed to not let sound disturb nearby classrooms. We introduced posing questions to the class and discussion groups, conducted by instructors from different fields - economics, architecture, languages. First of all, one exposed the theme through four panels: listening, feeling, tasting, smelling and seeing. The students should think about their bedrooms, their house, garden or playing spaces, and their school. In small group brainstorming, each identified a list of situations that best suited to their realities. In the middle, there was an informal debate on current issues related to noisy spaces, cars, buses, industries, the streets, local history, smoking, gas pollution, traffic and security. The activities were structured to emphasize collaborative, active, student- 
based learning. Every week, during two months, we collected the students' reports by individuals. At the end, they constructed a school mind map and drew symbols on a giant tissue map on the floor of classroom with pieces of cotton material (see Figure 1). The professors and the other graduated students accompanied the main activities answering questions, providing resources, and moving around the room, among students as necessary. All activities were registered with camera and shared with the UFMG students. Many teleconference lectures were done during three months (September, October and November).

\subsection{Nossa Senhora da Luz dos Pinhais, Municipal Elementary and Junior High School (2013)}

The pedagogical practices were carried out in partnership with a university teacher's project entitled "Basketball as an education practice to construct new values and bring about educational change" at the school. The project is broadly interdisciplinary, composed by educators and the junior high school students to deepen their own personal and professional learning. Our activities were outlined to fill the second school time (afternoon) which has a free curriculum. The characteristics of different practices offered to the students a comprehensive point of view about education/experience in diverse contexts.

Students from 9 to 13 years old changed their damaging view of studying all day and they felt rewarded with the opportunities to express their personal, feelings, reflections in different situations (see Figure 2). We worked hard to planning, developing, managing, using, and evaluating our practices. The needs and requirements to organize outings, class activities grounded in an educational, cultural and environmental interdisciplinary expertise and knowledge constitution helped us, university students and professors, to select and to assemble elements to form concepts properly within the school domain.

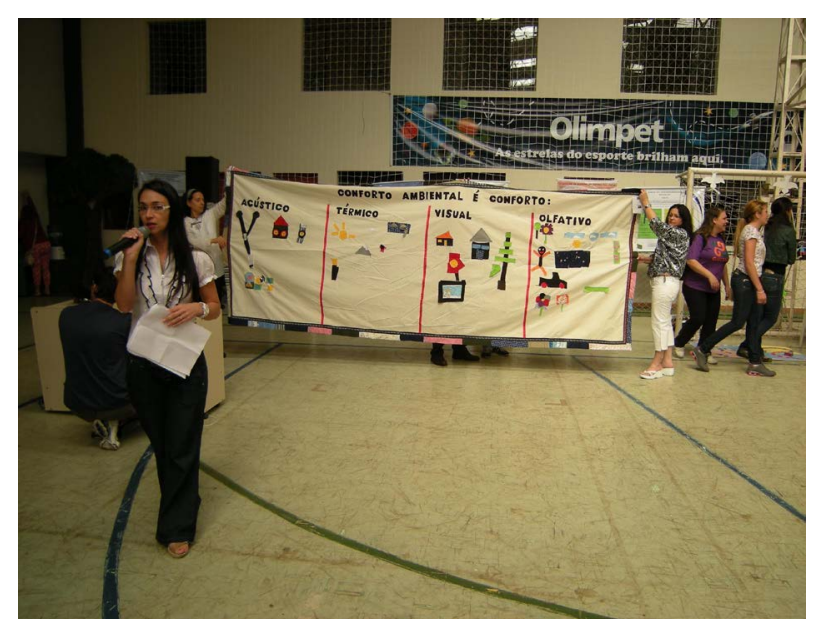

Figure 1. Final presentation of the environmental project.
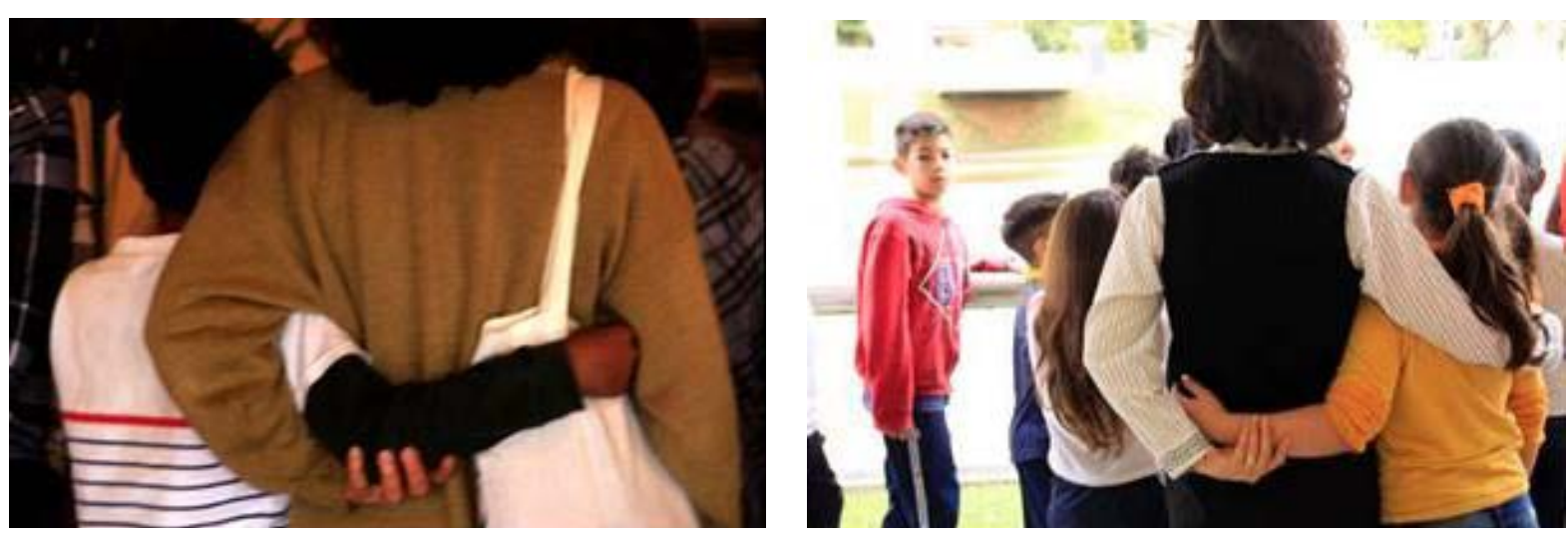

Figure 2. Teachers and students expressing their feelings in state of observation. 
First of all, we started with a regular activity that was to design in the school classroom. The dynamic was to work with the human body proportions (scale). Each one had to take measures (with tape measures) from each other and try to reduce them in the paper. It was really difficult for everybody, but the idea was to promote social relationships regarding our differences and similarities. The boys were much more interested than the girls. To accomplish the task they needed our help (see Figure 3).

The second meeting was an outing to the museum "Oscar Niemeyer". There, they participated in many activities like video interviews, to fabricate apparatus, a guided walk through the woods and internal visit and individual pictures (See Figure 4).

Similar, was the visit to the natural museum in the third outing where they had contact with dioramas from the Brazilian Ecosystems. Later on, they reminded many of the animals seen and commented with us the ones that most impressed them (see Figure 5).

Another special activity was at the Botanic garden, in the Environmental Education Space, promoted by the Municipal Environmental Department. Native painters, especially a lady painter from Curitiba, helped the students to paint an oil picture. Conferences accompanied the activity. In their classroom, we organized another activity to sign each other's paintings with architectural letters (see Figure 6).

Two outings were visits to universities. The first was in a private one-Universidade Positivo-where they assisted a presentation of the young girls belonging to the Rhythmic Gymnastics Club. They, as well, did exercise gymnastics monitored by the teachers and coaches: running, games, jumps, rollers. Some of them were afraid at the beginning but the will to be part of the sport activity changed their minds and motivated them to

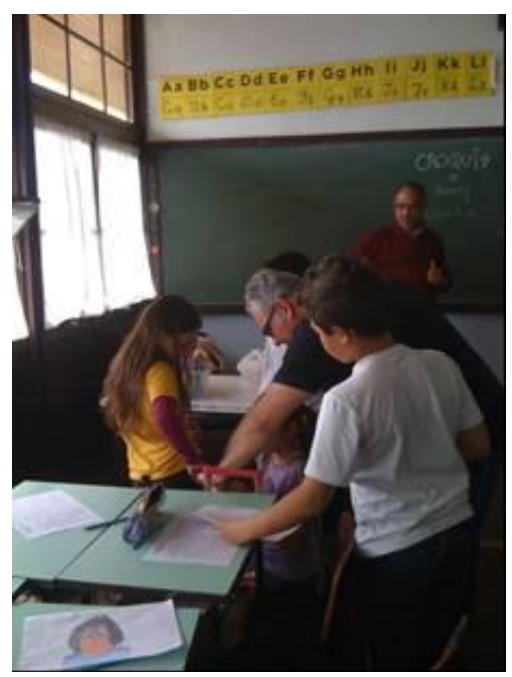

Figure 3. Teachers and students working together.
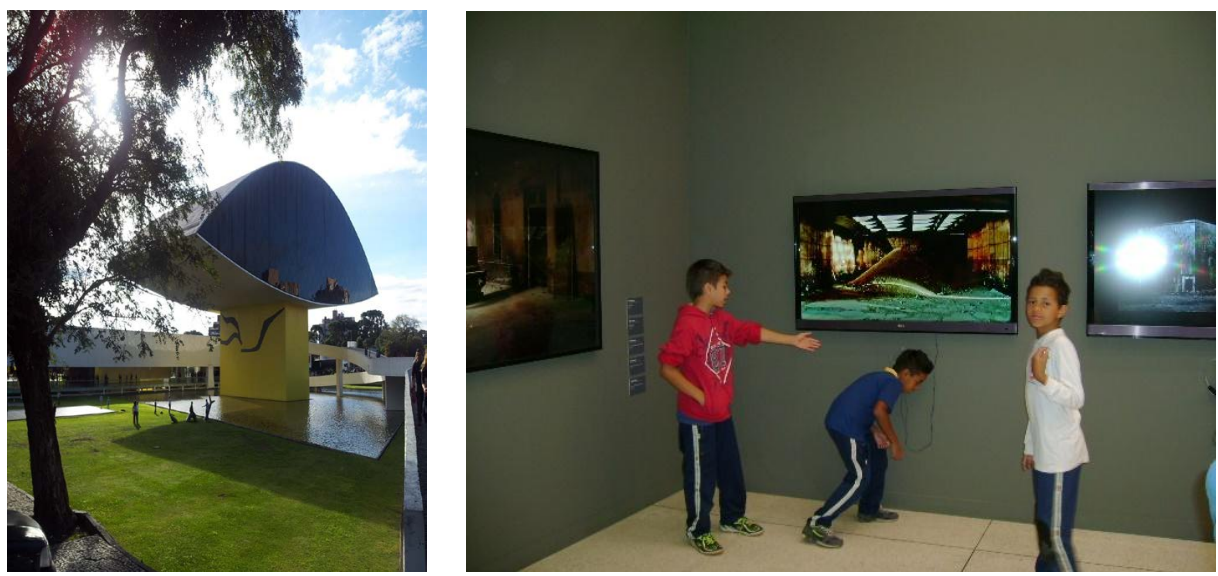

Figure 4. The eye museum of Curitiba inside and outside. 

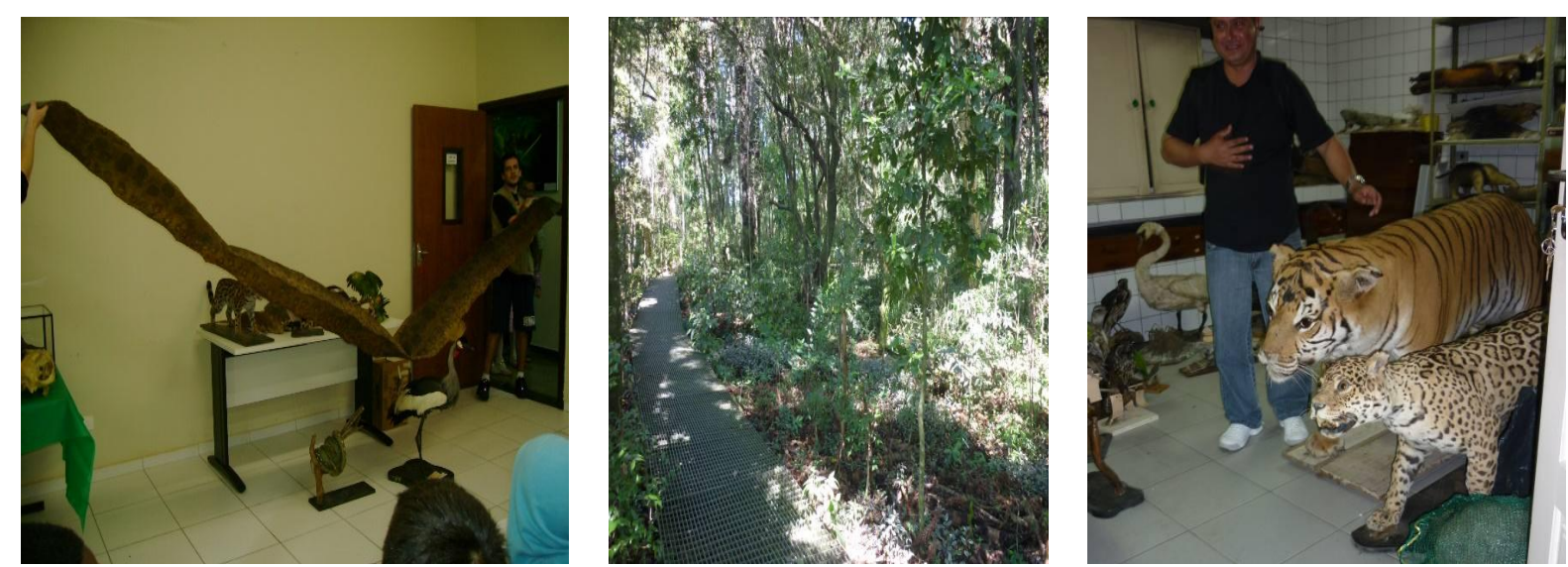

Figure 5. Curitiba Natural Museum outside and the taxidermies techniques for animals.
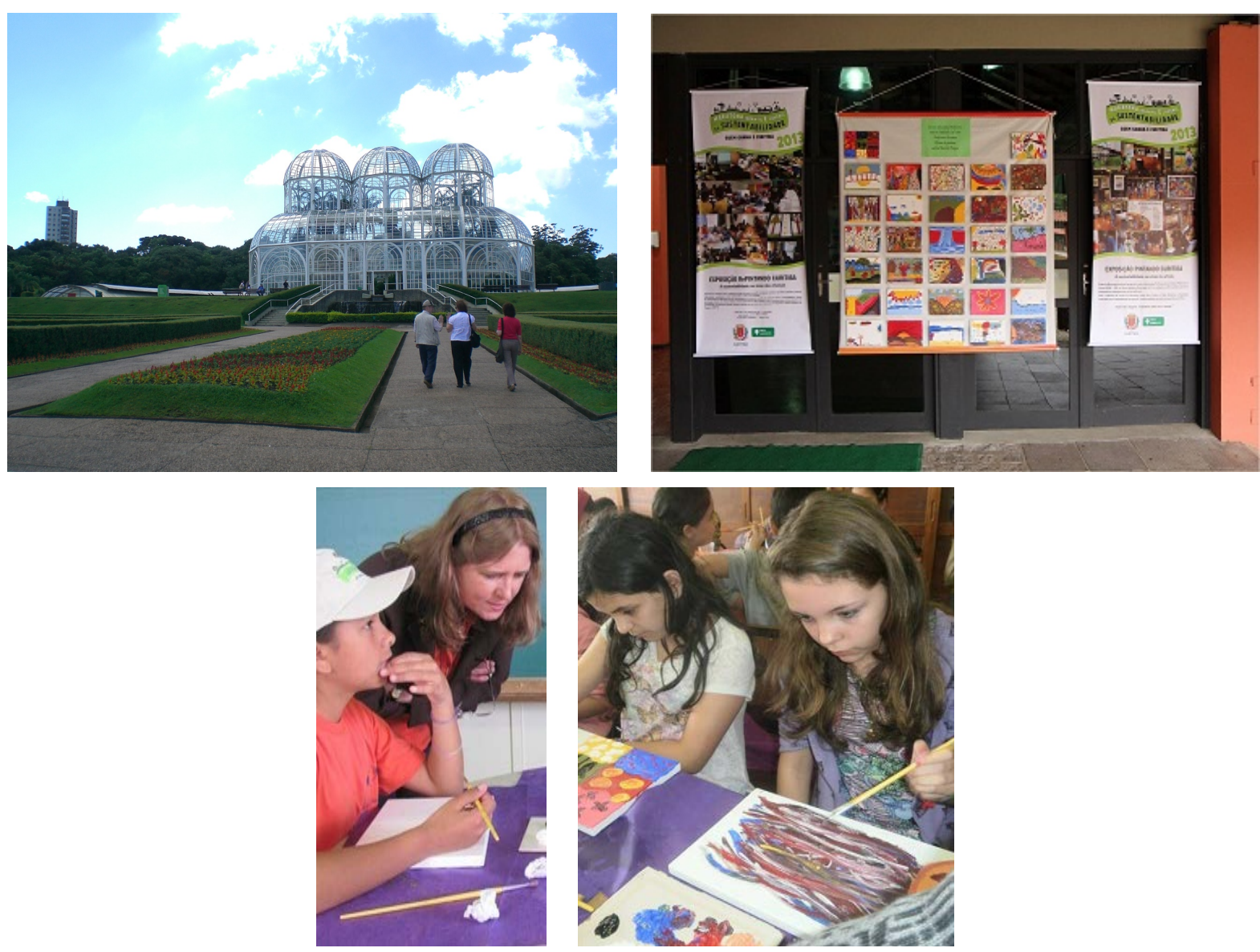

Figure 6. Activities at the Curitiba’ Botanical Garden.

make efforts to get a performance. Returning to school, in the bus, the students expressed their pleasure to play in such a nice place (see Figure 7).

At UTFPR, they could understand a little about the structure of the superior courses by doing a quick tour. We introduced the subject about their professional future. Some of the boys desire to be footballers; the girls dream to be architects and teachers. They talk with athletes with disabilities that were examples of effort and determination in following a career. They also participated at recreation activities like games, sport activities and exercises. At the University's restaurant they eat snacks and popcorn at "Didi” (see Figure 8). 


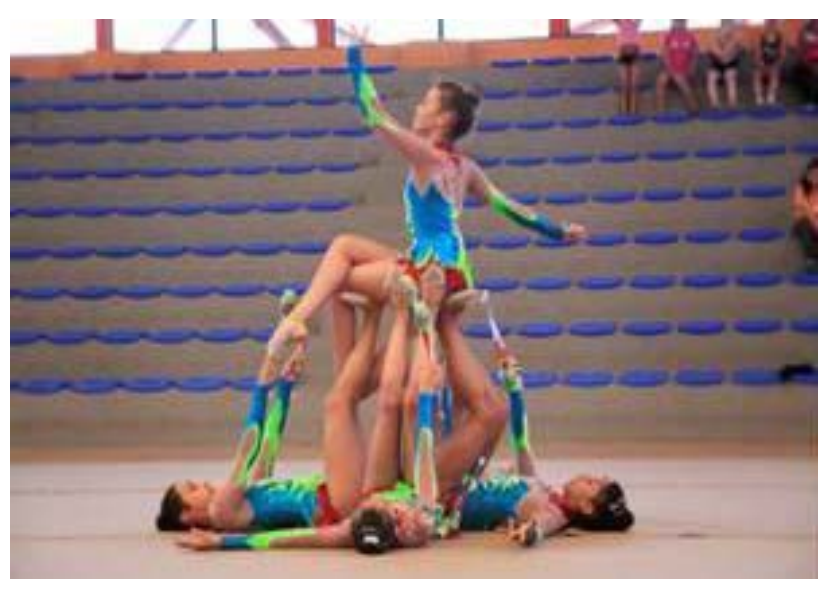

Figure 7. Children rhythmic gymnastics at positive university.
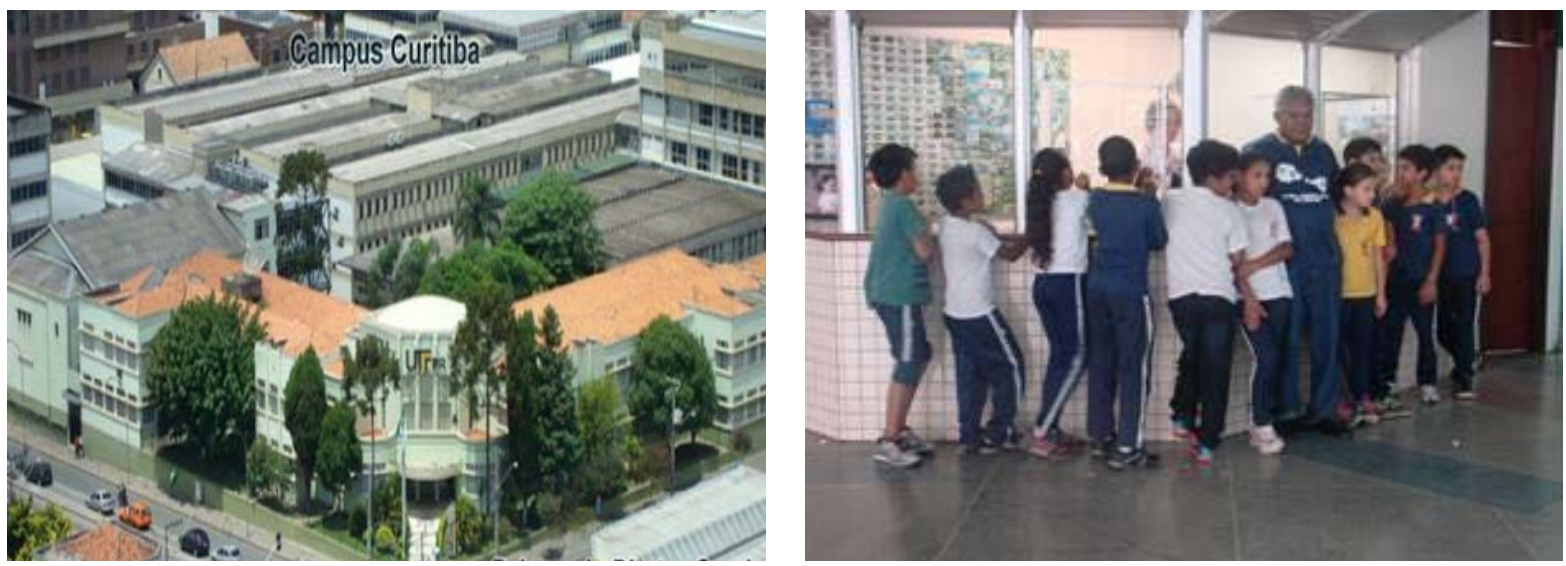

Figure 8. Didi with the children at UTFPR-Campus Curitiba.

The two last activities were at their classroom at school. They made a frame for their own pictures. They used materials such as inks, colored ribbons, glitter, reusable and recyclable waste, disposables materials, etc. They were pleased to see themselves in a video prepared with all activities done during the three months. That moment they felt supported to recognize themselves and distinguish their physical identities and reduce bullying that interferes in their way of being (Figure 9).

\subsection{Terra Firme, Papa João XXIII and Tereza Matsumoto Elementary and Junior High Schools (2014)}

This year students and professors from PPGTE/UTFPR promoted actions in three schools. There were workshops, educational, cultural and environmental interdisciplinary practices in order to mix culture, technology and environment aspects of life. At the private school, Terra Firme, the theme was urban agriculture and irrigation of the plants in holidays, when there is no one to irrigate. A system was installed in the school garden using alternative materials like a discharge box, aquarium and PVC tubes with digital automated sprinkler system timer. We also planted native trees in a municipal place exploring the concepts of soil, the pit size, the deepness, and watering to learn about better planting conditions. The school requested to the municipality its guard. Because some of the students had never planted a tree before, they had no abilities to manage the tools. It was a nice moment to talk to them about nature, values and coming experiences (Figure 10).

At the public school, "Tereza Matsumoto" situated close to the natural park called Reinhard Maack, we worked with the professional life of the German natural scientist Reinhard Maack (1892-1969), who was contracted by the Parana government to make the map of this Brazilian State. Our purpose of this kind of activity, and also a visit to an exposition, was to provide a reflection on the process of destruction of the Parana nature. 
The urban agriculture activities continued at the third school, Papa João XXIII. We organized a garden in appropriate boxes for small spaces and the students planted spices, such as marjoram, basil, oregano, mint, rosemary, lemon thyme, mint, among others. They had a great pleasure to mix the different kind of earth and the fertilizers (see Figure 11).

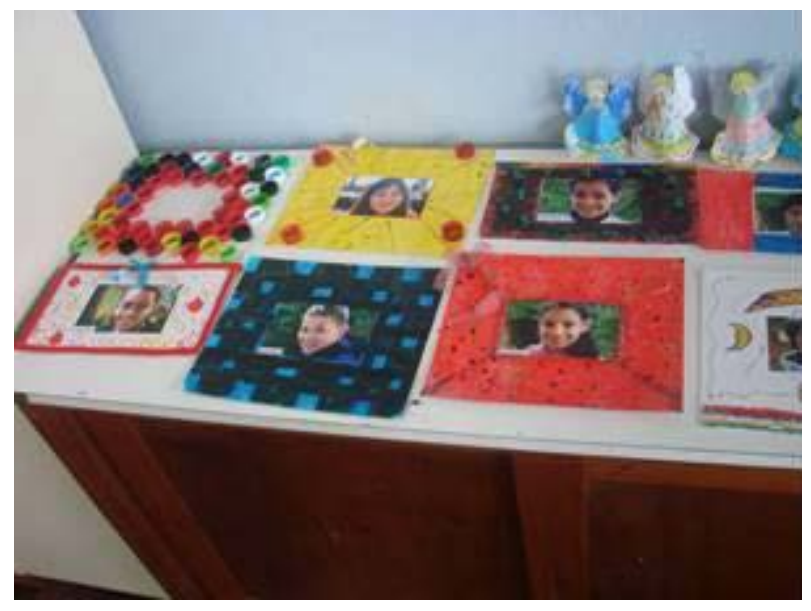

Figure 9. Students’ pictures and frames.
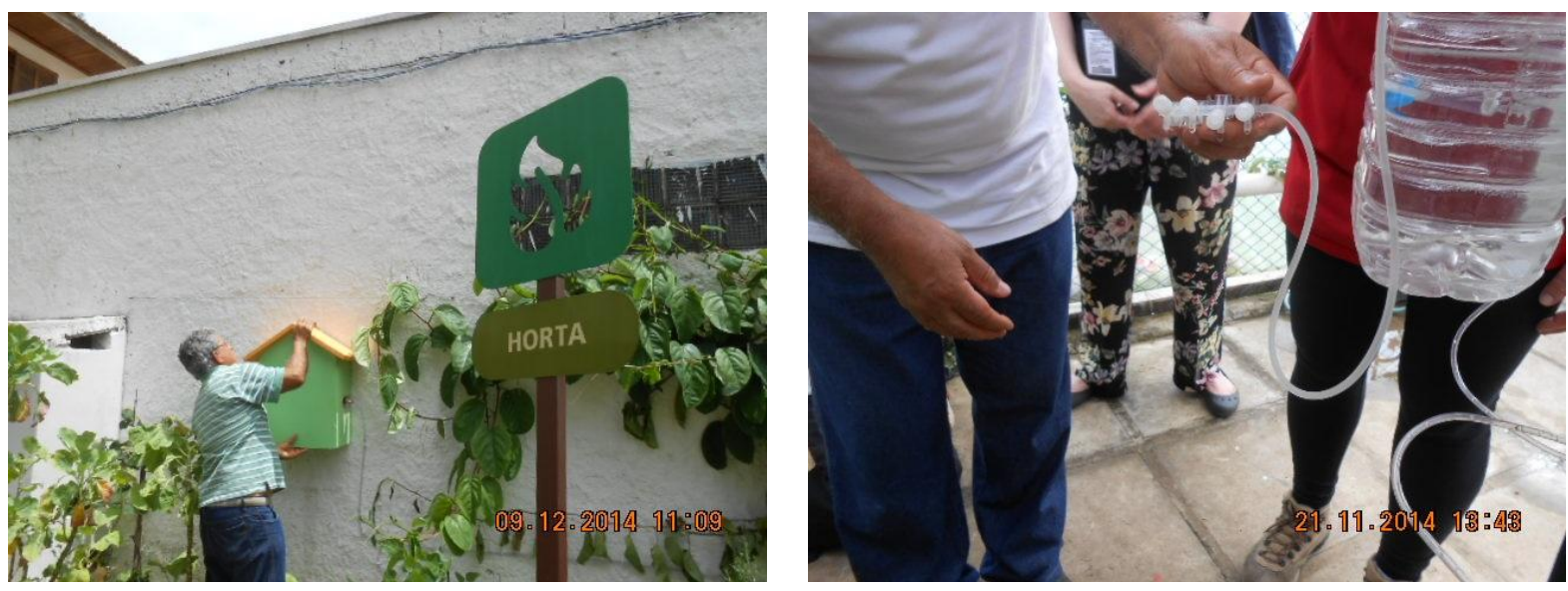

Figure 10. Preparing the irrigation system.

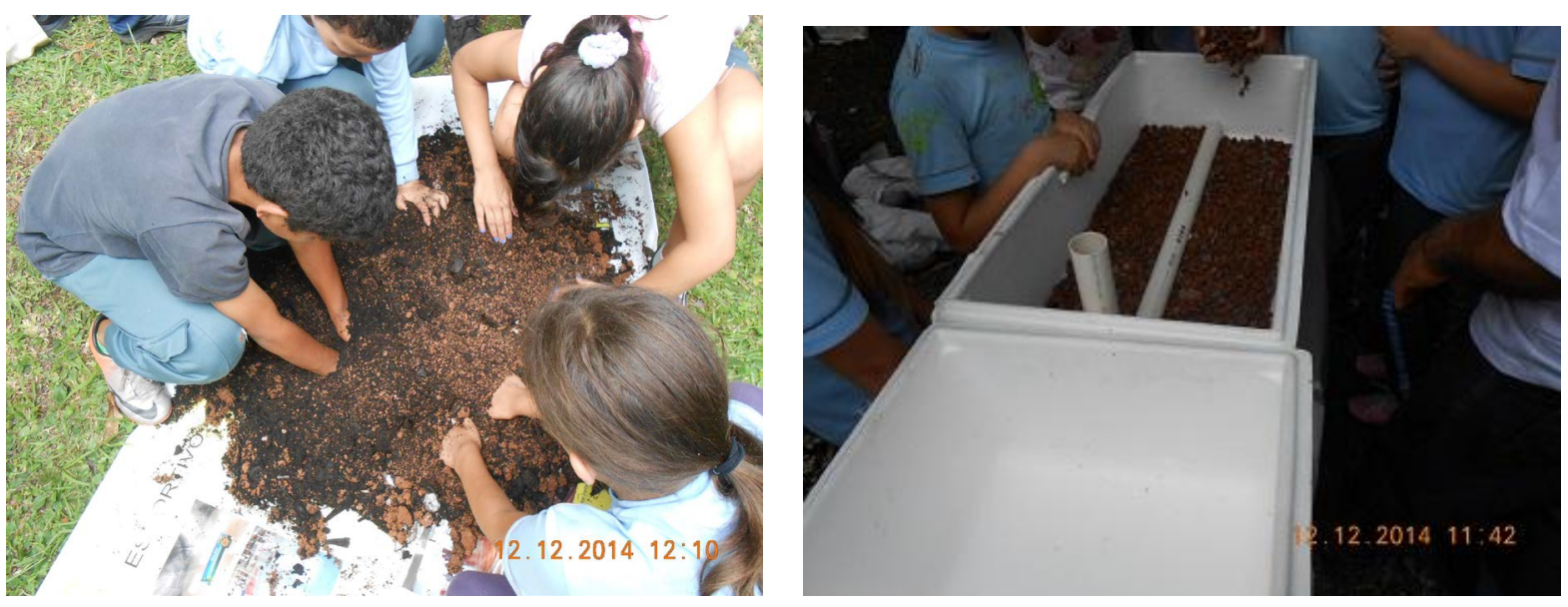

Figure 11. Children working in the planting stages. 
We explained about the environmental importance of nourishing the soil, with micromanage applications of water and fertilizer, and the environmental responses. More native trees were planted with solid organic substances and properly prepared substrate. They have been efficient and the results still show good effects. We called the project "seasoning life". We also planted trees (see Figure 12).

\section{Discussing the Case Studies}

The case studies emphasize the practice process and demonstrate that the interaction was dynamic involving together theories and methods, teaching and learning. It was a form to develop values and skills for students in the cultural, environment, social and political viewpoints. The focus was upon the links between conceptual and empirical aspects, always following different straightforward procedures considering the schools' needs. When we think about our good and bad experiences about the implementation of this type of learning, we conclude that the development and structure of the discipline provide us the encouragement to continue with this teaching methods and the multidisciplinary approach.

To contextualize the theoretical concepts, we used pedagogical tools shifting the emphasis from professors to student's activities with school junior students. We joined student's motivation and interest in a subject with the request of active learning. We believe the use of case studies were beneficial, enjoyable and challenging not only to the professors and the post-graduate students but also to the people who have worked in the experiences. The general comments heard from the schools people were that the structure of the course itself offered a wider range of background skills and it was easier to introduce confidence in their abilities to develop new dimensions to the teaching and learning activities. We evaluated whether our courses were meeting the objectives we set for them in terms of increasing student motivation, theoretical contents essentials to ensure good teaching. We did this by questionnaires and rapports (see Table 1 ).

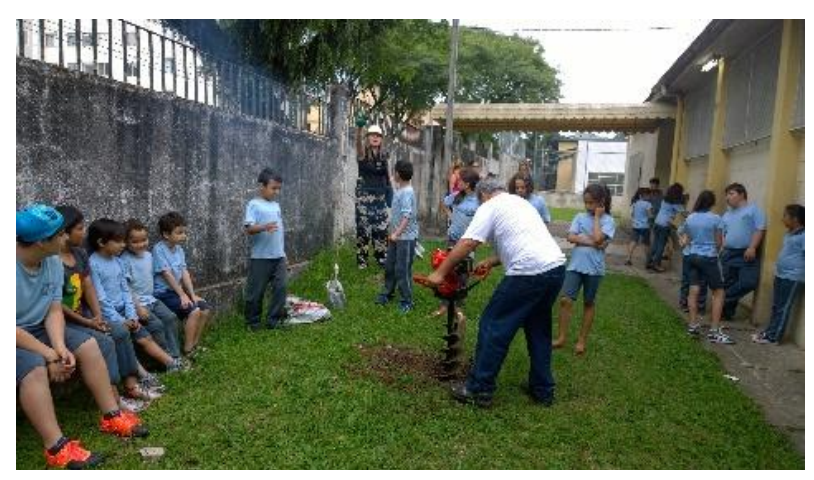

Figure 12. Planting at the box and digging the grave for planting a tree.

Table 1. Case studies perspectives and results - teaching and learning.

\begin{tabular}{|c|c|c|}
\hline Case study & Based teaching/learning & Problems found \\
\hline 1) UFMG Ecological Station (2011) & $\begin{array}{l}\text { We addressed one area that was needed to } \\
\text { incorporate training discussions. }\end{array}$ & $\begin{array}{c}\text { The students had information but the subject } \\
\text { was very polemic and complex. Myths and } \\
\text { true were confronted. }\end{array}$ \\
\hline $\begin{array}{l}\text { 2) São Miguel, municipal elementary } \\
\text { and junior high school (2012) }\end{array}$ & $\begin{array}{l}\text { New subject. Particularly important to all. } \\
\text { Progression of learning. }\end{array}$ & $\begin{array}{l}\text { To achieve more in-depth study would be } \\
\text { necessary. Greater guidance was required. }\end{array}$ \\
\hline $\begin{array}{l}\text { 3) Nossa Senhora da Luz dos Pinhais, } \\
\text { municipal elementary and junior high } \\
\text { school (2013) }\end{array}$ & $\begin{array}{l}\text { We spend less time in the original mode of } \\
\text { learning to dedicate to the composition of the } \\
\text { new topics and aspects including content } \\
\text { development. }\end{array}$ & $\begin{array}{l}\text { Bullying among the students reduced } \\
\text { participation in the activities. There was } \\
\text { too much information for everyone to } \\
\text { digest and assimilate. }\end{array}$ \\
\hline $\begin{array}{l}\text { 4) Terra Firme, Papa João XXIII and } \\
\text { Tereza Matsumoto elementary and } \\
\text { junior high schools (2014) }\end{array}$ & $\begin{array}{l}\text { The participants outlined further information to } \\
\text { their knowledge during the activities. Students } \\
\text { and professors discussed and shared their ideas } \\
\text { to progress in the application-focused subjects. }\end{array}$ & $\begin{array}{l}\text { We couldn't find specific learning problems. The } \\
\text { students' behaviors from the two schools were } \\
\text { completely different regarding the participation } \\
\text { and learning in the proposed activities. }\end{array}$ \\
\hline
\end{tabular}




\section{Conclusions}

Practices and theory are together in our discipline. Therefore, Best Practices is a wide range of individual and collective activities and procedures to achieve positive results regarding educational, cultural, environmental student's learning. The practices contain relevant research, innovation, critical elements and confidence in creativeness.

Even though future PHD'S think about intellectually challenging and rewarding disciplines at the full course, the myth that best practices can't complete their formation dissolved and they feel rewarded forever. Having a three-dimensional understanding of our discipline, students understand the purposes of their interaction reinterpreting teaching methods.

Their spontaneous and brilliant personal engagement comes from the skills to articulate on collective bodies of knowledge at the gradual preparation of a range of activities. On the other hand, the students benefit from a variety of approaches to teaching, different from the standardized teaching practices. What is important to learn from these practices is the opportunity to find out what works for each one in their learning process-particular viewpoints, observations, and interpretations - and in their future career: art, technique, sport. The students developed genuine understanding without thinking about what they were learning. We were not "teaching to the test” but to life. Student's satisfaction and happiness told us that teaching is something that advances over a career.

\section{References}

Austin, M. J., \& Rust, D. Z. (2015). Developing an Experiential Learning Program: Milestones and Challenges. International Journal of Teaching and Learning in Higher Education, 27, 143-153. http://www.isetl.org/ijtlhe/

Barbosa, M. C. S. (2014). Ethics in Ethnographic Research with Children: First Problematizations. Práxis Educativa, Ponta Grossa, 9, 235-245. http://www.revistas2.uepg.br/index.php/praxiseducativa

Bhattacherjee, A. (2012). Social Science Research: Principles, Methods, and Practices. Textbooks Collection. Book 3.

Heemann, A. (2001). The Body Thinks: An Essay about the Birth and Values Legitimation. Joinville: Univille.

Kolb, A. Y., \& Kolb, D. A. (2005). Learning Styles and Learning Spaces: Enhancing Experiential Learning in Higher Education. Academy of Management Learning \& Education, 4, 193-212. http://www.isetl.org/ijtlhe/ http://dx.doi.org/10.5465/AMLE.2005.17268566

Rickert, H. (1997). Science de la culture et science de la nature. Paris: Gallimard. 